\title{
Postgraduate teaching in the Department of Psychiatry, University of Keele
}

\author{
K. BARRETt, Consultant Neuropsychiatrist and Senior Lecturer in Psychiatry, \\ University of Keele, School of Postgraduate Medicine and Biological Sciences, \\ North Staffordshire Hospital Centre, Hartshill, Stoke-on-Trent ST4 7QB
}

\section{History of Keele}

Keele received its Charter as the University College of North Staffordshire in 1950. The first Vice Chancellor was Lord Lindsay, formerly the Warden of Magdalen College, Oxford. In the pre-war years Lindsay was a frequent visitor to the Potteries, presenting lectures within the Workers Education Association. He was unusual as an Oxford don not only in this respect but also in his approach to university education. He was closely involved in the development of the Modern Greats degree at Oxford and had strong views on the need for a broad liberal university education. Keele was founded on this principle as a teaching university offering a four year degree, the foundation year requiring students to study arts, sciences and humanities. At its inception the university was housed in a Victorian stately home, Keele Hall, and several ex-army huts. For the first decade of its life a "community of scholars" ethos was strongly emphasised and academics as well as students were required to live on campus. There were weekly small group student seminars involving academics from the three different disciplines. The academics look back on these seminars fondly, although it is not clear whether the students derived the same enjoyment from these interdisciplinary talking shops.

Research was very much a low priority in these early years but this was to change from the 1960 s onwards with the creation of postgraduate departments such as Communication and Neuroscience and in the 1970s Postgraduate Medicine. The Foundation year continued to be compulsory until the 1970 s, when it became optional. It remains popular. The strong teaching orientation of many departments persisted into the early 1980 sand was one of the reasons why the university appeared to be caught with its research trousers down in the mid-80s University Grant Committee Survey. Some departments sported only rather a scanty pair of research shorts while others, such as the Postgraduate Medicine, had very substantial research trousers indeed. The overall effect though was not impressive. Somewhat unfairly, no similar exercise was carried out on teaching - the academic goal posts had apparently moved since 1950 . A number of changes were, however, already under way before and following the appointment of Professor Brian Fender as the Vice Chancellor in 1985. These have recently included an administrative restructuring into academic schools and centres and a drive to increased interdisciplinary research, a logical development of the Keele teaching tradition.

\section{Postgraduate medical education in North Staffordshire}

A strong tradition of medical education has existed in the Potteries for well over three decades. The Potteries produced the first Postgraduate Medical Centre in the country in the early 1960s, and also developed the first general medical rotational training scheme in the country. Stoke also had one of the earliest GP schemes. A bid for the establishment of an undergraduate medical school in the early 1970s was unsuccessful and so the Department of Postgraduate Medicine was established in 1978. The Chair of Psychiatry was established in 1985 thanks to the lobbying and support of North Staffs consultants, with a senior lectureship the following year, and subsequent appointment of a senior research fellow and two lecturers (Cox, 1990). The size of the Department of Postgraduate Medicine and changes in University structure led to the creation of the School of Postgraduate Medicine and Biological Sciences in 1989 and the establishment of a formal Department of Psychiatry.

The interdisciplinary nature of teaching and research is exemplified by the creation of a number of academic centres including health planning and management, medical social anthropology and contemporary ethical studies. In addition many undergraduates pursue joint honours degrees and a wide variety of masters' degrees exist ranging from Victorian architecture to medical social anthropology, and medical ethics.

Clinical psychiatric training in Staffordshire centres around the Keele Registrar rotation which includes 20 registrar posts in Staffordshire, 
Shropshire and South Cheshire. There is teaching all day on Wednesdays which brings trainees together during university terms.

\section{Teaching needs in postgraduate psychiatry}

The Department of Psychiatry under Professor Cox is evolving a concept of general or generic psychiatry that has influenced our teaching, and has made its contribution to the formation at the new College Section of General Psychiatry.

The present situation is that "general adult psychiatry" consultants face a shrinking hospital base, leading in many cases to an ever more narrow brief within the general adult population. A further encouragement in this direction has been the rapid growth of sub-specialisation within psychiatry. Rehabilitation, forensic psychiatry, psychotherapy, psychogeriatric, substance abuse, have now been joined by liaison psychiatry and neuropsychiatry. Mental handicap and aspects of child psychiatry may be evolving into a new and fascinating animal called developmental psychiatry; meanwhile clinical psychology is annexing neurosis and the worried well.

\section{Postgraduate teaching}

Our teaching is almost entirely postgraduate which has given us a particular responsibility to produce innovative and clinically useful courses. During the past three years we have been working to this end.

\section{SHO and registrar training}

Our teaching takes place at present on one whole day, each week within university terms and takes the form of the following self-contained modules: basic psychiatry I, basic psychiatry II, applied neuroscience, applied behavioural neuroscience, the functional psychoses, neurosis and personality disorder, substance abuse and forensic psychiatry, social and cultural influences in psychiatry, developmental psychiatry, ageing and psychiatry, psychological and physical treatments in psychiatry concepts, models and practice, and research methods.

Basic psychiatry I and II provide, over the course of 40-50 hours, a comprehensive introduction to psychiatry and include seminars on psychological and physical treatments as well as introductions to the structure and management of mental health services and psychiatric ethics. Teachers from Keele, North Staffordshire and other local centres are included. The additional needs of trainees taking Part I (mock exams, exam techniques etc) are dealt with in out of term sessions. Modules designed to integrate basic and clinical science, and research on particular themes, include applied behavioural neuroscience which encompasses multi-disciplinary seminars on brain and behaviour and the clinical consequences of brain damage and malfunction. Social and cultural influences in psychiatry deals with the sociology and anthropology of mental disorder and the impact that societal and cultural factors have upon mental illness and health, and is also included as an optional course in the MSc in medical social anthropology. Developmental psychiatry presents a developmental model of psychiatric disorder and applies this to problems in childhood and adolescence, mental handicap and adult mental illness. These modules include speakers from other centres and we are trying to encourage interactive approaches where possible. As psychiatry is a discipline with its roots in biomedical, psychological and social sciences, our aim is to explore these in relation to the discipline as a whole and not simply to recruit sub-specialists. There is perhaps a parallel with traditional pre-clinical undergraduate training where teaching in biochemistry, physiology etc. of ten appeared to be designed to recruit candidates for intercalated degrees. The newer undergraduate schools attempt to overcome this by emphasising clinical relevance at an early stage. We are attempting to achieve a similar integration in relation to general psychiatry and this approach is formalised in two University qualifications which were approved by the Senate in 1990 .

\section{Diploma in General Psychiatry}

This Diploma is aimed at SHOs seeking a higher qualification in clinical psychiatry with the aim of pursuing a career in general practice or another discipline, the career psychiatrist who will simultaneously be sitting Part I Membership, or a service grade doctor seeking a limited alternative to full Royal College Membership. It requires attendance at the two basic psychiatry modules and four additional half day, one term modules; a whole day over 30 weeks or a half day over two years. Diploma candidates have to complete at least one six month post in psychiatry with a trainer in an approved scheme who will have to provide a satisfactory report. Course assessment and examinations include the preparation of five audited cases of approximately 3,000 words each on different disorders, including a brief resume of the relevant literature in relation to their aetiology and management. Similar case studies are used by the Royal Colleges of Obstetrics and Gynaecologists and General Practitioners. The preparation of the case studies will be supervised by a member of the Department. Candidates will be examined orally by an external examiner on these cases and on other clinical material. An essay paper, probably in an extended essay format, will also be completed and the Department reserves the right to conduct a formal clinical 
examination if felt appropriate. Successful candidates will be awarded a Diploma by the University and may then apply for extension to the Masters' Degree.

\section{MSc in General Psychiatry}

The aim of the MSc is to emphasise the multidisciplinary origin of psychiatry by teaching in an integrated fashion and to engender a critical approach to research and practice. As with the Diploma, the Masters follows the pattern for such Degrees in the University of Keele. This will include six additional teaching modules attended over one or two years and a one week research methods course. A 10,000 word dissertation will be prepared on an agreed topic, supervised by a member of the Department, with an associated research protocol. There will be two three-hour essay papers and an oral examination. The written examinations will include the presentation of research material for critical evaluation, as well as questions covering sub-specialty topics. An oral examination centres on the dissertation and other clinical material. The University also has a Master's Degree by thesis and we currently have a number of external and internal students registered for such a degree. This may be extended to a PhD.

\section{Senior registrar training and beyond}

The University of Keele has Masters in Medical Ethics and Medical Social Anthropology which could be suitable for senior registrars or consultants. We have had discussions with several departments on Masters' degrees providing courses relevant to the higher training and sub-specialisation senior registrar level. The first of these, Brain, Behaviour and
Development, a Masters in Clinical and Developmental Neuropsychiatry, is now being planned. This will provide teaching, probably in three day Units over one year, with related course work and followed by a supervised research project leading over one or more years to a thesis, oral and written examinations. A legitimate sibling of this will be a Diploma/Masters on Social and Cultural Influences in Psychiatry and preliminary discussions on the possibility of such a course are taking place. Senior Lecturer posts are to be advertised in 1990/91 and these planned developments depend on successful appointments to these posts.

Finally, the presence of the Centre for Health Planning and Management at Keele offers the possibility of developing modules and other courses on management, audit, quality assurance and resource utilisation.

\section{Comment}

The Keele Department of Psychiatry is still growing and we are aware both of our youth and the special responsibilities and privileges of being part of a Postgraduate School without formal undergraduate medical teaching commitments (lest we forget, all academics in the School are subject to a three or five yearly academic performance reviews). This paper has outlined current and planned teaching. It remains to be seen whether or not our 'products' will have a 'market' in 1990s postgraduate psychiatry.

\section{Reference}

Cox, J. L. (1990) Psychiatry at Keele: germination of a new department. Psychiatric Bulletin, 14, 489-490.

\section{Audit in practice}

Medical audit was the topic of the Open Forum which preceded the meeting of the Education Committee on 12 March 1990. Dr Michael Robinson, of the London School of Hygiene and Tropical Medicine, dealt with more general aspects and Dr Ann Gath, Registrar of the College and Chairman of the Medical Audit Working Party, with aspects of particular relevance to psychiatry.

\section{Medical audit: basic principles and current methods}

Medical audit has been defined as "the systematic, critical analysis of the quality of medical care, including the procedures used for diagnosis and treatment, the use of resources, and the resulting outcome for the patient" (Department of Health, 1989). Although the concept has recently been brought into 